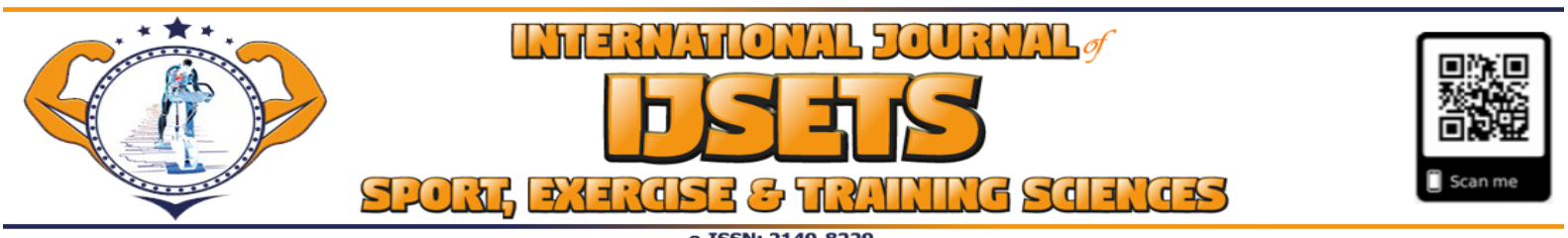

\title{
Ranking of the education and social benefits, the responsibilities, the professional competencies of sport counseling process in the opinion of sports and physical education experts
}

\author{
Dana BADAU ${ }^{1}$, Adela BADAU ${ }^{2}$
}

\begin{abstract}
Aim: The aim of this study was assessing and ranking in terms of practical importance of the responsibilities and professional skills of sports counselor included in the specific occupational standard, in the vision of sports professors and coaches; identifying the level of correlation between responsibilities and professional skills of sports counselor.

Methods: The research included 471 specialists in physical education and sports training the professional competencies and responsibility questionnaire of the sports counselor was applied (qrepsc) and divided in 2 scales: scale 1: Responsibilities of the sports counselor and scale 2 professional competencies of sports counselor, assessed by participant using SPSS and the Likert scale.

Results: Cronbach's Alpha for the questionnaire QRCPSC of the scale 1 Sports counselor responsibilities questionnaire was $\alpha=.947$, and for scale 2 Professional competencies of sports counselor was $\alpha=.963$, all value suggesting that the items had high internal consistency. It is guiding sportspeople in solving the professional problems which they have in different moments of their career and giving sports advice for the professional problems.

Conclusion: Career and practical development in sports counseling is based on the impact which responsibilities and professional competency of sports counselors are reflected in the vision of experts with major influence on student's mentality, sports recreational and physical education experts.
\end{abstract}

$\underline{\text { Article Info }}$

Received: 23.10 .2020

Accepted: 14.12 .2020

Online Published: 15.12 .2020

DOI: $10.18826 /$ useeabd. 815406

\section{INTRODUCTION}

The development of sports counseling process fits in the actual trends, by the diversify of new professions, imposed by the evolution of sports phenomenon (Badau, 2014). Sports counseling is focusing on the growth of the athlete as an individual, including the interpersonal problems related to performance, training and also professional sports career (Hinkle, 1999; Vasiliu, \& Ciolca, 2014). Counseling targets the effectiveness of sports management performance, of time and style of life that the athlete has and solving the problematic situations specific to the sports career (Harris, 2015; Shurts, \& Shoffner, 2004).

The process of sports counseling targets the direct interventions on athlete's life, highlights the role of sport in human development, collaboration and communication efficiency with the athletes by the point of view of performance and athletes career (Petitpas, \& Tinsley, 2014). In the point view of experts, the sport counselor is a qualified person that based on specialty knowledge and specific abilities and competences offers assistance to some persons or groups involved in sport and recreational activities, with the view to improve the fitness and optimize the sport career (Hilliard, Redmond, \& Watson, 2019; Lindo et. Al., 2019).

In present, the values, social norms, thinking patterns and styles of life of the practicants of sports and recreational activities are constantly changing, so also the process of counseling suffers major modifications which impose knowledge expansion with practical abilities of the counselors in relation with present tendencies and individual and group requirements (Lowery, 2019; Tao, \& Wei, 2011). The achievement of these goals reclaim from counselor's point of view a good capacity of: understanding,

The role and contributions of each authors as in the section of IJSETS Writing Rules "Criteria for Authorship" is reported that: 1. Author: Contributions to the conception or design of the paper, data collection, statistical analysis, interpretation of the data writing of the paper and final approval of the version to be published paper; 2. Author: Contributions to the conception or design of the paper, data collection, statistical analysis, interpretation of the data writing of the paper and final approval of the version to be published paper.

${ }_{1}^{1}$ Corresponding author: "Petru Maior" Faculty of Sciences and Letters, George Emil Palade University of Medicine, Pharmacy, Science and Technology, Targu Mures/Romania ORCID ID: 0000-0002-1881-3531

2"Petru Maior" Faculty of Sciences and Letters, George Emil Palade University of Medicine, Pharmacy, Science and Technology, Targu Mures/Romania, ORCID ID: 0000-0002-1656-5060 
improvement, structuring of knowledge, communication, learning, adaptability, creativity, etc. (Wu, 2011; Tod, 2007).

The process of sports counseling associated with psychological process and health promotion activities (Rus, et. al. 2019; Badau, Prebeg, Mitic, \& Adela, 2015), can contribute to the optimization of life quality (Camarda, \& Badau, 2010; Badau, Ungur, \& Badau, 2015) and also to the effectiveness of different activities and the career of physical education practicants (Talaghir, Iconomescu, Stoica, 2018; Dreve1, Stoica, Blejan, \& Ene, 2019; Badau, \& Badau, 2018; Corlaci, Hidi, Vasilescu, \& Stoica, 2013). The essential condition is that this process of counseling to be accomplished by experts with a high professional and educational level.

The study consists in highlighting the impact which responsibilities and specific components of the process of sports counseling has in the opinion of experts from pre-university and university educational system and sports coaches. Specialty literature highlights the insufficient information regarding the importance of responsibilities and specific competencies, performed by sports counselors for the efficiency of their activity and the important role this profession has in physical education. We consider that structuring responsibilities and specific competencies will determine the awareness by sports counselors of the image that this activity has in the vision of experts from physical education field. Elaboration of occupational standard (Badau, Larion, \& Petre, 2014), didn't have a base for scientific research regarding competencies and responsibilities of sports counselor, but it was based only on the necessity of including these professions in relation with the dynamic working market in recreational physical educational field. The arguments which were anteriorly mentioned were at the base of achieving this study, which we hope it will highlight on scientific data the area of responsibility and competency of sports counselor. Actual and modern tendencies regarding competency expansion and also the level of professional specialists from the physical education field targets to be more dynamic and create new professional and occupational opportunities imposed by social and economic dynamic evolution and especial of the sport phenomenon.

Our study targeted three specific aims:

- Evaluation and ranking by the point of view of practical importance of responsibilities of sports counselor included in specific occupational standard in the vision of sports professors and coaches;

- Professional competency impact evaluation of sports counselor specific for occupational standard and their ranking by the point of view of practical importance, in the expert's vision from physical education field;

- Identifying the correlation level between specific responsibilities and professional competencies of sports counselor in the context of new occupation in sports field.

\section{METHOD}

\section{Research Design}

The research was conducted between April - October 2019 and it included 471 specialists in physical education and sports training who were kind to answer the questionnaire. The inclusion criteria targeted active specialists with superior studies which were finished. The excluding criteria were if they not completed all items of questionnaires. Questionnaires were individually administered and were completed online. The questionnaire was created with Google Forms, being collected and processed only the completed dates for whole questionnaire. Participation in the study was voluntary and progress of the study was in compliance with the study which follows the principles of the Declaration of Helsinki and their amendment.

\section{Participants}

Specialists from Romania, from which 357 (75.8\%) physical education professors from pre-university and university and $112(24.2 \%)$ active sport coaches. All participants at the study are active experts with a seniority in educational and sports system for at least 2 years, age between $23-56,269(57.2 \%)$ male and $202(42.8 \%)$ female.

\section{Measures}

In the study we use the questionnaire for assessing the professional responsibilities and competences of the sports counselor (QRCPSC), divided in 2 scales: scale 1 responsibilities of sports counselor and scale 2 professional competencies of sports counselor. Responsibilities and competencies were 
identified by occupational standard approved in 2012 by National Authority for Qualifications, from Romania, base group 2269 COR code 226911 (Badau, Larion, \& Petre, 2014).

Scale 1 Responsibilities of sports counselor include 10 items which targeted the main responsibilities and roles of sports counselor. Scale 2 professional competencies of sports counselor includes 7 items which correspond to the main activities and competencies that derive from them, specific to the sports counselor involved in sports, recreational and institutional activity. The questionnaire was designed with Likert scale (5), 1 representing the minimum level of evaluation of practice impact, and 5 the highest level of appreciation of practice impact.

\section{Statistical analysis}

The data were processed by using IBM-SPSS 24, and the statistical analysis included the index: the arithmetic average $(\mathrm{X})$, standard deviation (SD), Student- $\mathrm{t}$ test $(\mathrm{t})$, Corrected Item-Total Correlation (r), Cronbach's Alpha $(\alpha)$. The value of statistical significance was set at $p<0.05$. Pearson Inter-Item Correlation Matrix index had been choosing to highlight the correlation between the items of each scale of QRCPSC. Interpretation of Pearson correlation as (Evans, 1996), suggests for the absolute value of r: .00-.19 very weak, .20-.39 weak $.40-.59$ moderate $.60-.79$ strong $.80-1.0$ very strong. The reliability or the internal consistency of the questionnaire was calculated using the Cronbach's alpha statistical index $(\alpha)$. For internal consistency, Cronbach's coefficient alpha to test reliability exceeded 0.70 for all measures. Descriptive statistics (mean \pm SD) was calculated for all variables of study.

\section{RESULTS}

Cronbach's Alpha for the questionnaire QRCPSC of the scale 1 responsibilities of sports counselor questionnaire was $\alpha=.947$, and for scale 2 professional competencies of sports counselor was $\alpha=.963$, all value suggesting that the items had high internal consistency. Also all values of Cronbach's Alpha for each item highlights a high internal consistence, $\alpha$ values being contained between .939 si .960 (Table 1). Statistical processing of the results of the questionnaire QRCPSC for both scales and for the study sample highlighted the results statistically significant for $p<0.05$. the results recorded by the Corrected Item-Total Correlation index reflect a strong and very strong, the lowest values being .693, and the highest .888 (Table 1). According Table 1, the average value of the whole questionnaire was 3.897; for the scale 1 Sports counselor responsibilities questionnaire for the average value was $\mathrm{x}=3.835$, and for scale 2 professional competencies of sports counselor was $x=3.985$. The highest score on scale 1 The responsibilities of the sports counselor was registered for item 3. It orients the athletes in solving the professional problems they face at different times of their career $\mathrm{x}=4.066$, and the lowest average score of item 8 Assisting the athletes during the negotiations $x=3,560$. The highest score on scale 2 The professional competencies of the sports counselor was registered for item 3 Granting of consultancy to the athletes on professional issues $x=4.173$, and the lowest average score for item 4 Monitoring the sports preparation process $\mathrm{x}=3.830$

Table 1. Descriptive statistics for the results of the questionnaire QRCPSC assessing the responsibilities' and professional competences of sport counselor

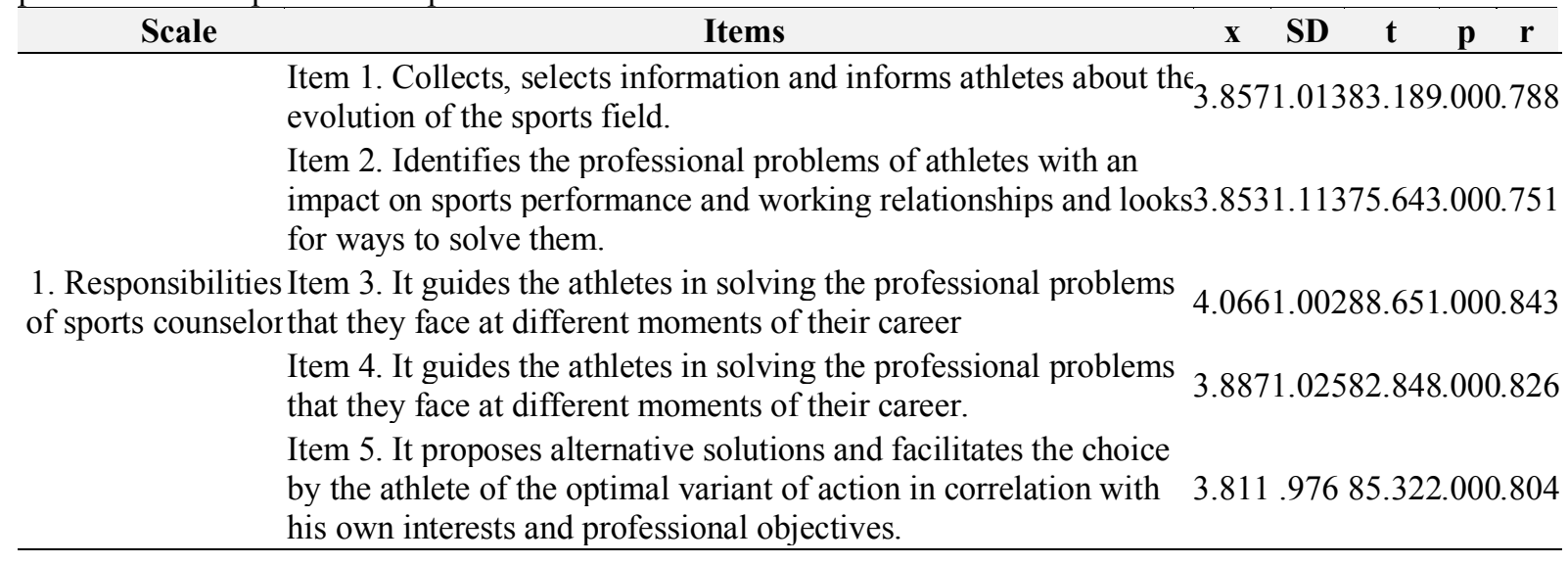




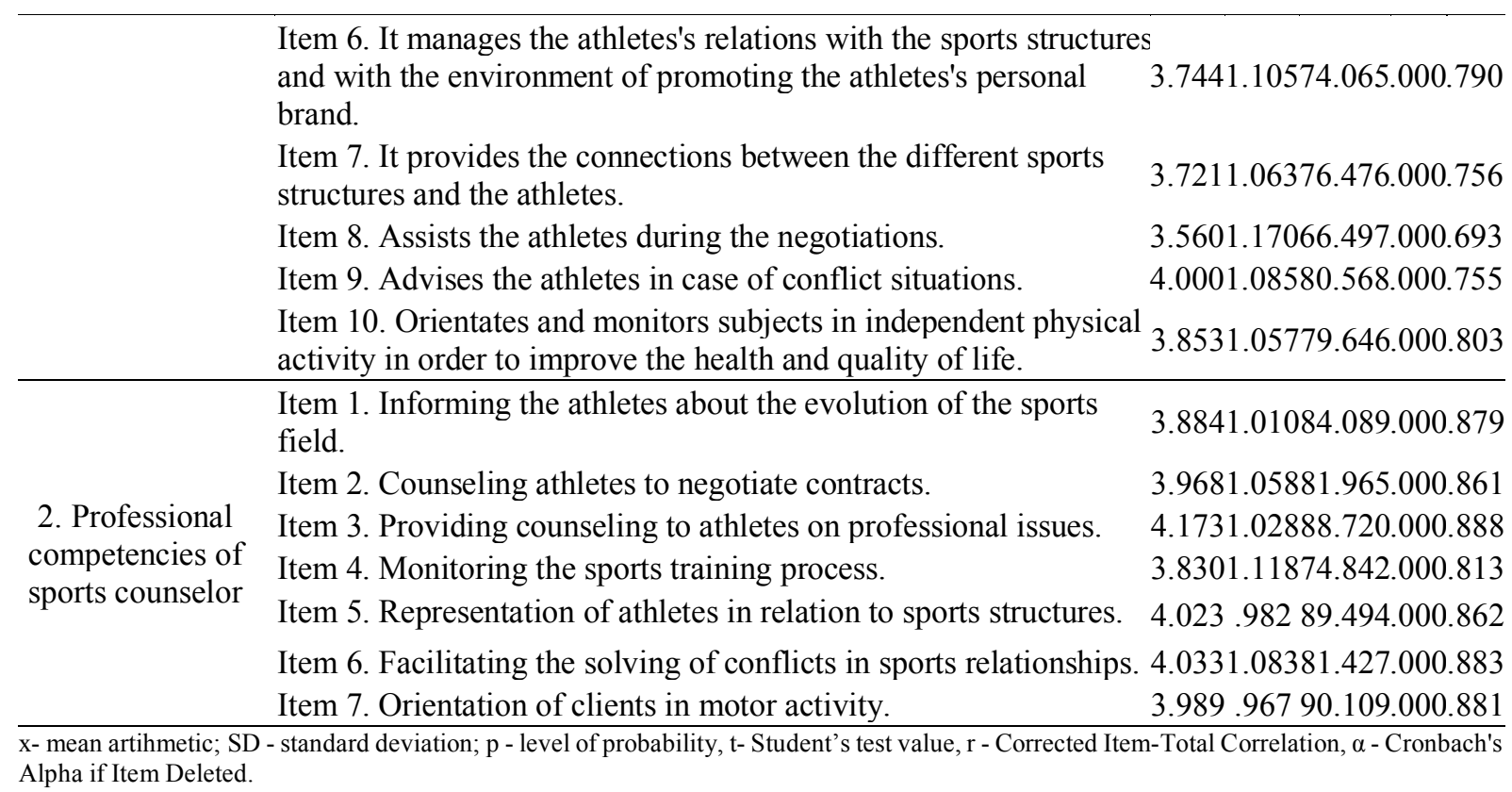

The questionnaire for assessing the professional responsibilities and competences of the sports counselor was evaluated with maximum of points 5 by 196 specialists, with 4 points by 74 specialists, with 3 points by 166 specialists, with 2 points by 28 specialists and with 1 point by 7 specialists in the field of physical education and sport (Table 2). For scale 1 The responsibilities of the sports counselor of the QRCPSC questionnaire the ratio of the specialists who gave maximum score was 181 specialists, 4 points were given by 80 specialists, 3 points were given by 171 specialists, 2 points were given by 28 specialists and only 11 specialists evaluated it with 1 point. For the scale The professional competencies of the sports counselor of the QRCPSC questionnaire the ratio of the specialists who awarded the maximum point was 217 specialists, 4 points were given by 67 specialists, 3 points by 157 specialists, 2 points by 27 specialists and only 3 specialists evaluated with 1 point. (Table 2 ).

Table 2. Statistical analysis of the ratio of responses according to the Likert scale (5) on each item at the 2 scales of the QRCPSC questionnaire

\begin{tabular}{|c|c|c|c|c|c|c|}
\hline \multirow{2}{*}{ Scale } & \multirow[b]{2}{*}{ Items } & \multicolumn{5}{|c|}{ Ratio of answers N(\%) } \\
\hline & & 5 points & 4 points & 3 points & 2 point & 1 point \\
\hline \multirow{15}{*}{$\begin{array}{l}\text { Responsibilities } \\
\text { of sports } \\
\text { counselor }\end{array}$} & $\begin{array}{l}\text { Item 1. Collects, selects information and informs athletes about } \\
\text { the evolution of the sports field. }\end{array}$ & $172(36)$ & $\begin{array}{c}30 \\
(41.7)\end{array}$ & $\begin{array}{c}152 \\
(31.8)\end{array}$ & $\begin{array}{c}44 \\
(9.2)\end{array}$ & $\begin{array}{c}0 \\
(0)\end{array}$ \\
\hline & $\begin{array}{l}\text { Item 2. Identifies the professional problems of athletes with an } \\
\text { impact on sports performance and working relationships and } \\
\text { looks for ways to solve them. }\end{array}$ & $191(40)$ & $\begin{array}{c}84 \\
(17.6)\end{array}$ & $\begin{array}{c}162 \\
(33.9)\end{array}$ & $\begin{array}{l}24 \\
(5)\end{array}$ & $\begin{array}{l}17 \\
(3.6)\end{array}$ \\
\hline & Item 3. It guides the athletes in solving the professional & 237 & 56 & 163 & 20 & 0 \\
\hline & problems that they face at different moments of their career & $(49.6)$ & $(11.7)$ & $(34.5)$ & $(4.2)$ & $(0)$ \\
\hline & Item 4 . It guides the athletes in solving the professional & 193 & 64 & 203 & 10 & 8 \\
\hline & problems that they face at different moments of their career. & $(40.4)$ & (13.4) & $(42.5)$ & $(2.1)$ & $(1.7)$ \\
\hline & Item 5. It proposes alternative solutions and facilitates the & 157 & 100 & 203 & 10 & 8 \\
\hline & $\begin{array}{l}\text { choice by the athlete of the optimal variant of action in } \\
\text { correlation with his own interests and professional objectives. }\end{array}$ & $(32.8)$ & $(20.9)$ & $(42.5)$ & $(2.1)$ & $(1.7)$ \\
\hline & Item 6. It manages the athletes's relations with the sports & 166 & 92 & 164 & T & $12(2.5)$ \\
\hline & $\begin{array}{l}\text { structures and with the environment of promoting the athletes's } \\
\text { personal brand. }\end{array}$ & $(34.7)$ & $(19.2)$ & $(34.3)$ & $(9.2)$ & \\
\hline & $\begin{array}{l}\text { Item 7. It provides the connections between the different sports } \\
\text { structures and the athletes. }\end{array}$ & $153(32)$ & $\begin{array}{l}108 \\
(22.6)\end{array}$ & $148(31)$ & $\begin{array}{c}69 \\
(14.4)\end{array}$ & $\begin{array}{c}0 \\
(0)\end{array}$ \\
\hline & Item 8 . Assists the athletes during the negotiations. & $\begin{array}{c}144 \\
(30.1)\end{array}$ & $\begin{array}{c}74 \\
(15.5)\end{array}$ & $196(41)$ & $\begin{array}{l}34 \\
(7.1)\end{array}$ & $\begin{array}{l}30 \\
(6.3)\end{array}$ \\
\hline & Item 9. Advises the athletes in case of conflict situations. & 218 & 84 & 155 & 0 & 21 \\
\hline & & $(45.6)$ & $(17.6)$ & (32.4) & $(0)$ & (4.4) \\
\hline & $\begin{array}{l}\text { Item 10. Orientates and monitors subjects in independent } \\
\text { physical activity in order to improve the health and quality of } \\
\text { life. }\end{array}$ & $\begin{array}{c}178 \\
(37.2)\end{array}$ & $\begin{array}{c}99 \\
(20.7)\end{array}$ & $\begin{array}{c}166 \\
(34.7)\end{array}$ & $\begin{array}{c}23 \\
(4.8)\end{array}$ & $\begin{array}{c}12 \\
(2.5)\end{array}$ \\
\hline
\end{tabular}




\begin{tabular}{|c|c|c|c|c|c|c|}
\hline & $\begin{array}{l}\text { Item } 1 \text {. Informing the athletes about the evolution of the sports } \\
\text { field. }\end{array}$ & $\begin{array}{c}186 \\
(389)\end{array}$ & $\begin{array}{c}84 \\
(17.6)\end{array}$ & $\begin{array}{c}175 \\
(36.6)\end{array}$ & $\begin{array}{c}33 \\
(69)\end{array}$ & $\begin{array}{c}0 \\
(0)\end{array}$ \\
\hline & Item 2. Counseling athletes to negotiate contracts. & 218 & 59 & 179 & 12 & 10 \\
\hline & & $(45.6)$ & (12.3) & (37.4) & $(2.5)$ & (2.1) \\
\hline & Item 3. Providing counseling to athletes on professional issues. & 280 & 22 & 155 & 21 & 0 \\
\hline & & $(58.6)$ & $(4.6)$ & $(32.4)$ & $(4.4)$ & $(0)$ \\
\hline mpetencies of & fItem 4. Monitoring the sports training process. & 184 & 98 & 139 & 45 & 12 \\
\hline sports counselor & & $(38.5)$ & $(20.5)$ & $(29.1)$ & $(9.4)$ & $(2.5)$ \\
\hline & Item 5. Representation of athletes in relation to sports structures. & 216 & 77 & 165 & 20 & 0 \\
\hline & & $(45.2)$ & $(16.1)$ & $(34.5)$ & $(4.2)$ & (0) \\
\hline & Item 6. Facilitating the solving of conflicts in sports & 246 & 44 & 146 & 42 & 0 \\
\hline & relationships. & $(51.5)$ & $(9.2)$ & $(30.5)$ & $(8.8)$ & $(0)$ \\
\hline & Item 7. Orientation of clients in motor activity & 200 & 94 & 163 & 21 & 0 \\
\hline & & $(41.8)$ & $(19.7)$ & $(34.1)$ & $(4.4)$ & $(0)$ \\
\hline
\end{tabular}

$\mathrm{N}$ - number of subjects, $\%$ - percentage

We presented the ratio of answers on each item to highlight the distribution of expert opinions and identify the most relevant or lowest values. The responsibilities of the sports counselor, according to the occupational standard (Table 3) reveal positive correlation between all items. The correlation was only average for item 2 with 8, otherwise all values showed strong and very strong correlations between items, values being between 0.5 and 0.9 . All correlations were statistically significant.

Table 3. Descriptive statistics of Inter-Item Correlation Matrix of scale 1 Responsibilities of the sports counselor of the QRCPSC questionnaire, according to the occupational standard

\section{Items}

Item 1. Collects, selects information and informs

athletes about the evolution of the sports field.

Item 2. Identifies the professional problems of athletes with an impact on sports performance and working relationships and looks for ways to solve them.

Item 3. It guides the athletes in solving the professional problems that they face at different moments of their career

Item 4. It guides the athletes in solving the professional problems that they face at different moments of their career

Item 5. It proposes alternative solutions and facilitates the choice by the athlete of the optimal variant of action in correlation with his own interests and professional objectives

Item 6. It manages the athletes's relations with the sports structures and with the environment of promoting the athletes's personal brand.

Item 7. It provides the connections between the different sports structures and the athletes.

Item 8 . Assists the athletes during the negotiations.

Item 9. Advises the athletes in case of conflict situations.

Item 10. Orientates and monitors subjects in independent physical activity in order to improve the health and quality of life.

All correlations were significant at the 0.01 level.
Item1 Item2 Item3 Item4 Item5 Item6 Item7 Item8 Item9 Item10

\begin{tabular}{|c|c|c|c|c|c|c|c|c|c|}
\hline- & .650 & .768 & .613 & .629 & .641 & .641 & .509 & .751 & .676 \\
\hline .650 & - & .714 & .694 & .626 & .579 & .551 & .436 & .624 & .768 \\
\hline .768 & .714 & - & .733 & .775 & .621 & .632 & .504 & .813 & .701 \\
\hline .613 & .694 & .733 & - & .870 & .677 & .691 & .650 & .546 & .665 \\
\hline .629 & .626 & .775 & .870 & - & .553 & .629 & .698 & .593 & .614 \\
\hline .641 & .579 & .621 & .677 & .553 & - & .718 & .723 & .584 & .768 \\
\hline .641 & .551 & .632 & 691 & .629 & .718 & - & .630 & .561 & .593 \\
\hline .509 & .436 & .504 & .650 & .698 & .723 & .630 & - & .541 & .534 \\
\hline .751 & .624 & .813 & .546 & .593 & .584 & .561 & .541 & - & .646 \\
\hline .676 & .768 & .701 & .665 & .614 & .768 & .593 & .534 & .646 & \\
\hline
\end{tabular}

In case of scale 2 Professional competences of the sports counselor of the QRCPSC questionnaire, according to the occupational standard, analysis of the correlation between the items reveals positive 
and statistically significant correlation between all items. All the values showed strong and very strong correlations between the items, the values being between 0.6 and 0.9 (Table 4 ).

Table 4. Descriptive statistics Inter-Item Correlation Matrix of scale 2 - The professional competencies of the sports counselor of the QRCPSC questionnaire, according to the occupational standard

\begin{tabular}{|c|c|c|c|c|c|c|c|}
\hline Items & Item 1 & Item 2 & Item 3 & Item 4 & Item 5 & Item 6 & Item 7 \\
\hline Item 1. Informing the athletes about the evolution of the sports field. & - & .793 & .816 & .834 & .771 & .747 & .807 \\
\hline Item 2. Counseling athletes to negotiate contracts. & .793 & - & .752 & .753 & .849 & .787 & .757 \\
\hline Item 3. Providing counseling to athletes on professional issues. & .816 & .752 & - & .789 & .726 & .864 & .863 \\
\hline Item 4 . Monitoring the sports training process. & .834 & .753 & .789 & - & .705 & .697 & .682 \\
\hline Item 5. Representation of athletes in relation to sports structures. & .771 & .849 & .726 & .705 & - & .834 & .807 \\
\hline Item 6 . Facilitating the solving of conflicts in sports relationships. & .747 & .787 & .864 & .697 & .834 & - & .872 \\
\hline Item 7. Orientation of clients in motor activity. & .807 & .757 & .863 & .682 & .807 & .872 & - \\
\hline
\end{tabular}
All correlations were significant at the 0.01 level.

\section{DISCUSSION}

The results of the study allowed us to perform a hierarchy on scientific data based on the opinion of the experts in the field of physical and sports activities and on the identification that between all responsibilities and the respective ones between the professional competences, there is a strong correlation. The ranking of the responsibilities of the sports counselor in the view of the experts in the field of physical and sports activities, based on the results of the study is the following: Item 3. Orientates the athletes in solving the professional problems that they face at different moments of their career, Item 9. Advise the athletes in case of conflict situations, Item 4. Orientates the athletes in solving the professional problems they face in different moments of their career, Item 1. Gathers, selects the information and informs the athletes on the evolution of the sports field, Item 10. Orientates and monitors subjects in the independent physical activity in order to improve health and quality of life, Item 2. Identifies the professional problems of athletes with an impact on sports performance and working relationships and looks for ways to solve them, Item 5. Proposes alternative solutions and facilitates the choice by the athlete of variants and optimal actions in correlation with their own professional interests and goals, Item 6. Manages the athlete's relationships with the sports structures and with the environment of promoting the athlete's personal brand, Item 7. Ensures the connections between the different sports structures and the athlete, Item 8 . Assists the athletes during the negotiations. Regarding the professional competences, their hierarchy in the view of the experts on the importance is: Item 3. Providing consultancy to athletes on professional issues, Item 6. Facilitating the solution of conflicts from sports relations, Item 5. Representation of athletes in relation to sports structures, Item 7. Clients orientation regarding motor activity, Item 2 . Counseling athletes to negotiate contracts, Item 1. Informing athletes about the evolution of the sports field, Item 4. Monitoring the sports preparation process.

Our study complements the research in the field of sports counseling. Numerous studies have highlighted the role and benefits on the quality of life, learning and health of the sports counseling process on different categories of students (Hilliard, Redmond, \& Watson, 2019; Kliethermes et.al, 2019; Menke, \& Germany, 2019; Proper et.al. 2004). Studies have shown that sports counseling based on individualized protocols has positive influences at all levels of physical activity practice and physical fitness (Miller, Ogilvie, \& Adams, 2000; Proper, 2003). In accordance with the results of our study regarding the responsibilities of the sports counselor, studies conducted on adults have shown that the counseling process has led to an increased in self-esteem, awareness of personal needs and preferences, increased interest in promoting an active, correct and healthy proactive lifestyle (Wagner, Mullen, \& Sims, 2019; Bilon, \& Kargul, 2012; McBride, \& Hays, 2012; Dinç, \& Özbek, 2019).

Joining the few empirical studies on the importance of the process of sports counseling for experts, the results of this study fill a gap in the literature on this topic.

Strengths: the large number of experts in the field of physical and sports activities included in the study, evaluation of all responsibilities and competencies included in the occupational standard; identification of the correlations between the items of the two scales of the QRCPSC questionnaire; identification of the imported practice based on which we have achieved the ranking of the important responsibilities and competences of the sports counselor. Expansion of future research on the efficiency of sports counseling activity at all activity levels and in different population categories. 
Limits of the study: not including in the study the other categories involved in the sports activity, like professional athletes, amateur athletes, managers of sports institutions, students; failure to evaluate the relationship between experts in the field of physical and sports activities with sports counselors.

\section{CONCLUSION}

The results of the study contributed to the hierarchy of professional responsibilities and competencies of the sports counselor in the expert's vision, which facilitates the efficiency of the counseling process and identifies the activities and roles relevant from the point of view of the sports counseling process. The development of the practice in the career of sports counseling is based on the impact that the responsibilities and professional competences are reflected in the vision of the experts with major influences on the mentality of the students, athletes and recreational practitioners of physical and sports activities.

The implementation and development of the occupation of sports counselor is now a necessity, which can contribute to the efficiency of the sports management process, of the sports training, of the recreational activities and implicitly of promoting a sporting, proactive and healthy lifestyle.

\section{PRACTICAL APPLICATION}

Based on the results of this study, we consider that a revision of the occupational standard is required based on the impact on which the responsibilities and professional competencies are reflected in the expert's view and in relation to the trends of the sporting phenomenon, of physical education and of recreational activities.

\section{REFERENCES}

Badau, D. (2014). Sport counseling - a new approach to improve the performances, Annals of "Dunarea De Jos" University of Galati, 15(1), 24-28.

Hinkle, J.S. (1999). Sports Counseling: Helping Student Athletes, in Book: Promoting Optimum Mental Health through Counseling: An Overview, CAPS Publications, Inc., P.O. Box 26171, Greensboro, NC 27402-6171, 131-138.

Vasiliu, A.M., \& Ciolca, C. (2014). Student's Perception on Career Opportunities, Procedia Social and Behavioral Sciences, 117, 700-704.

Harris, P.C. (2015). Black Males and Intercollegiate Athletics: an Exploration of Problems and Solutions, Diversity in Higher Education, 16, 1-19.

Shurts, W.M., \& Shoffner, M.F. (2004) Providing Career Counseling for Collegiate Student-Athletes: A Learning Theory Approach, J. Career Dev., 31(2), 95-109.

Petitpas, A.J., \& Tinsley, T.M. (2014). Counseling interventions in applied sport psychology. In J. L. Van Raalte \& B. W. Brewer (Eds.), Exploring sport and exercise psychology, Washington, DC, US: American Psychological Association, 241-259

Hilliard, R.C., Redmond, L.A., \& Watson, J.C. (2019). The Relationships Among Self-Compassion, Stigma, and Attitudes Toward Counseling in Student-Athletes, J. Clin. Sport Psychol., 13(3), 374389.

Lindo, N.A., Ceballos, P.L., Blalock, S., Conner, C., Edwards, J., Spellings, M., Webster, L., \& Opiola, K. (2019). Students? perceptions of career counselling: an examination of a graduate curriculum in the United States, Brit. J. Guid. Couns., 13(3), 374-389.

Lowery, K. (2019). Educators' perceptions of the value of coach mindset development for their wellbeing, International Journal of Mentoring and Coaching in Education, 8(6), 310-324.

Tao, Y., \& Wei, C. (2011). Several Relations to be Handled in Sports College's Counselor Work, Second International Conference on Education and Sports Education, 3, 93-95.

Wu, X.X. (2010). A Study of Development of Comprehensive Competence of College Counsellors in the New Situation, Proceedings of the third International Conference on Education Management Science and Engineering, 959-963. 
Tod, D. (2007). The long and winding road: Professional development in sport psychology, Sport Psychol., 21(1), 94-108.

Rus, A.V., Stativa, E., Parris, S.R., Pennings, J.S., O'Hern, S.B., Burcea, G., \& Popa, C.O. (2019). Awareness of Same-Sex Relationships between Children in Romanian Long-Term Residential Centers, Rev. Cercet. Interv. Soc., 66, 9-21.

Badau B., Prebeg, G., Mitic, D., \& Adela, B. (2015). Fitness index and VO2max of physical education students. Ovidius University Annals, Series Physical Education and Sport/Science, Movement and Health, 15(2 S1), 246-252.

Camarda, D., \& Badau, D., (2010). Entertainment and sports animation--effects and benefits. Ovidius University Annals, Series Physical Education \& Sport/Science, Movement \& Health, 10(2), 859862

Badau, A., Ungur, R.N., \& Badau, D. (2015). Influence of water gymnastics on strength development. Palestrica of the Third Millennium Civilization \& Sport, 16(3), 235-240

Talaghir, L.G., Iconomescu, T.M., Stoica, L. (2018). The Sports Game-A Means of Developing Motor Skills in Secondary School: A Study on Strength and Endurance, Revista Romaneasca pentru Educatie Multidimensionala, 10(4), 228-240.

Dreve1, A., Stoica, M., Blejan, C., \& Ene D. (2019). Theoretical aspects of total training integrated in the physical training of the football player. Discobolul - Physical Education, Sport and Kinetotherapy Journal, 58(4), 43-47.

Badau, D., \& Badau, A. (2018). Identifying the incidence of exercise dependence attitudes, levels of body perception, and preferences for use of fitness technology monitoring. International journal of environmental research and public health, 15(12), 2614.

Corlaci, I., Hidi, I. L., Vasilescu, D., \& Stoica, M. (2013). The Motivational Profile of Individual Practitioners of Sports Performance. Procedia-Social and Behavioral Sciences, 84, 1646-1650.

Badau, D., Lariona, A., \& Petre, C. (2014). Standard ocupational “Consilier sportiv”, group 2269, cod COR 226811, level CNC/6CEC, http://www.anc.edu.ro/standarde_app/SO/consilier\%20sportiv.pdf, (Accesed 20-25.09.2019)

Evans, J.D. (1996). Straightforward statistics for the behavioral sciences. Belmont, CA, US: Thomson Brooks/Cole Publishing Co., 28-29.

Hilliard, R.C., Redmond, L.A., \& Watson, J.C. (2019). The Relationships Among Self-Compassion, Stigma, and Attitudes Toward Counseling in Student-Athletes, J. Clin. Sport Psychol., 13(3), 374389.

Kliethermes, S.A., Dugas, L.R., LaBella, C.R., Alawad, N., Pasulka, J., \& Jayanthi, N. (2019). Benefits and challenges of serial sports training risk assessment and counselling in kids: the TRACK randomised intervention study, Br. J. Sports Med., 53(4): 243-249.

Menke, D.J., \& Germany, M.L. (2019). Reconstructing Athletic Identity: College Athletes and Sport Retirement, J. Loss Trauma., 24(1): 17-30.

Proper, K.I., de Bruyne, M.C., Hildebrandt. V.H., Ivan der Beek, A.J., Meerding. W.J., \& Van Mechelen, W. (2004). Costs, benefits and effectiveness of worksite physical activity counseling from the employer`s perspective, Scand J Work Environ Health, 30(1), 36-46.

Miller, T.W., Ogilvie, B., \& Adams, J. (2000). Sports psychology: Issues for the consultant. Consulting Psychology Journal: Practice and Research, 52(4), 269-276.

Proper, K.I., Hildebrandt, V., Van der Beek, A.J., Twisk, J.W.R., \& Van Mechelen. W. (2003). Individual counseling and active lifestyle: a randomized controlled trial in a worksite setting. $\mathrm{Am} \mathrm{J}$ Prev Med, 24(1), 218-26.

Wagner, N.J., Mullen, P.R., \& Sims, R.A. (2019). Professional Counselors' Interest in Counseling Older Adults, Adultspan Journal, 18(2), 70-84.

Bilon, A., \& Kargul, J. (2012). Socio-cultural contexts for defining the role of counsellors, Studia Poradonznawcze/Journal of Counsellogy, 1(1), 265-287. 
McBride, R.G., \& Hays, D.G. (2012). Counselor Demographics, Ageist Attitudes, and Multicultural Counseling Competence Among Counselors and Counselor Trainees, Adultspan Journal, 11(2), 77-88.

Dinç, A., \& Özbek, O. (2019). Occupational socialization and psychological capital levels of physical education teachers. International Journal of Sport Exercise and Training Sciences - IJSETS, 5(2), 58-67.

\section{CITATION OF THIS ARTICLE}

Badau, D., \& Badau, A., (2020). Ranking of the education and social benefits, the responsibilities, the professional competencies of sport counseling process in the opinion of sports and physical education experts. International Journal of Sport, Exercise \& Training Sciences - IJSETS, 6(4), 129-137. DOI:10.18826/useeabd.815406. 